\title{
Breast imaging reports for malignant lesions: are we maintaining recommended $\mathrm{BI}$-RADS $^{\circledR}$ lexicon standards?
}

This article was published in the following Dove Press journal:

Cancer Management and Research

6 November 2012

Number of times this article has been viewed

\author{
Imrana Masroor' \\ Muhammad Azeemuddin' \\ Saima Sakhawat' \\ Madiha Beg' \\ Saba Sohail ${ }^{2}$ \\ Rashid Ahmed ${ }^{3}$ \\ Irfan-Ul-Haq ${ }^{4}$ \\ Javed Mehboob ${ }^{5}$ \\ 'Radiology Department, Aga Khan \\ University Hospital, ${ }^{2}$ Radiology \\ Department, Civil Hospital, ${ }^{3}$ Advanced \\ Radiology Clinic, ${ }^{4}$ Radiology \\ Department, Pakistan Naval Station \\ Shifa Hospital, ${ }^{5}$ Karachi Institute of \\ Radiotherapy and Nuclear Medicine, \\ Karachi, Pakistan
}

Background: The purpose of this study was to evaluate mammography reports for diagnosed breast cancer cases in major government and private centers in Karachi, Pakistan, with respect to concordance with the Breast Imaging Reports And Data System (BI-RADS ${ }^{\circledR}$ ) lexicon.

Methods: A prospective, descriptive, multicenter study was conducted in the radiology sections of the Aga Khan University Hospital, Pakistan Naval Station Shifa Hospital, Advanced Radiology Clinic, Karachi Institute of Radiotherapy and Nuclear Medicine, and Civil Hospital Karachi between May and October 2010 after approval from the ethical review committee of Aga Khan University. Mammograms reported as BI-RADS category 4 and 5 were included in the study. Mammograms reported as BI-RADS category 0, 1, 2 and 3 were excluded. Fifty reports were collected from each center. Data were collected about the clinical indication, breast density, location and description of the lesion, calcification, and comments on axillary lymph nodes. This description was compared with the BI-RADS lexicon.

Results: The mean age of the patients was $50 \pm 12$ years. The clinical indication, breast parenchymal density, lesion location, and presence of calcification were better described by the private centers, while description of lymph node status was better stated by the government centers. This difference was statistically significant, except for lesion description. The description of masses by the two reporting groups was comparable.

Conclusion: Mammographic reporting of malignant breast lesions in the private sector is more in line with the BI-RADS lexicon, as compared with government sector hospitals in Karachi, Pakistan. Lymph node documentation was better in government sector reports.

Keywords: breast cancer, BI-RADS ${ }^{\circledR}$, mammography, public sector, private sector

\section{Introduction}

Breast cancer is the most frequent cancer of women in Karachi, Pakistan. Breast cancer accounts for one-third of all cancers in females. The incidence of breast cancer is very high in Karachi and the highest in Asia. ${ }^{1}$ Early diagnosis is the most important factor in increasing the survival rate. Regular mammographic screening has shown great promise in this regard by decreasing breast cancer mortality by $15 \%-20 \%{ }^{2,3}$ There are no government-funded screening programs for breast cancer in Pakistan. The diagnosis and treatment of breast cancer is based partly on imaging findings. This provides information for an accurate diagnosis and subsequent surgical and neoadjuvant treatment. $^{4}$

In order to standardize mammographic reporting, the American College of Radiology developed Breast Imaging Reporting and Data System (BI-RADS ${ }^{\circledR}$ ) lexicon terms to describe breast density, lesion features, impressions, and recommendations for further
Correspondence: Imrana Masroor Radiology Department, Aga Khan University Hospital, Stadium Road, Karachi 74800, Pakistan Email imrana.masroor@aku.edu 
patient management. ${ }^{5}$ Broadly speaking, there are two final assessment categories. Assessment is considered incomplete when the radiologist orders further imaging to make a definitive mammographic diagnosis. Assessment is considered complete when the radiologist is sure of the diagnosis and categorizes mammograms from 1 to 6 . BI-RADS categories 1 and 2 denote a benign lesion and category 3 requires short-term follow-up of the patient. Categories 4 and 5 define a suspected malignancy, and biopsy or other appropriate action is advised. Category 6 depicts a biopsy-proven malignancy. ${ }^{5}$

BI-RADS has been used for over a decade to provide a uniform and standardized system for reporting of mammographic findings. ${ }^{4}$ It also helps in advising on subsequent management for patients, which is necessary for adequate treatment. ${ }^{6}$

Previous research on BI-RADS has evaluated interobserver and intraobserver variability in description of lesions. ${ }^{7,8}$ There have been studies examining the consistency between assessment categories and management recommendations. ${ }^{9}$ A study conducted in Australia examined the quality and completeness of the contents of imaging reports with respect to BI-RADS. ${ }^{4}$ However, anecdotal experience suggests that the quality of breast imaging reports is highly variable and information relevant to patient care may be omitted or partially reported in these reports. ${ }^{4}$

To the best of our knowledge, no such study has been conducted in Pakistan. Accurate reporting and appropriate recommendations for further workup are of the utmost importance, given that many patients either self-refer or are referred by primary care physicians, and mammography reports are the driving force for appropriate treatment at the outset. In Pakistan, breast imaging services are provided by either private imaging centers or government-funded (public sector) services that operate independent of treatment centers. Except for a minority of tertiary care hospitals in Pakistan, no data confirm the involvement of a radiologist in multidisciplinary meetings, whether post diagnosis or during treatment planning. In our system, primary care physicians are responsible for breast imaging and referral of the patient to a breast surgeon if necessary. Therefore, it is imperative that mammography reports communicate adequate and clear information to primary care physicians and treatment teams.

We conducted this study to evaluate the mammography reports of representative newly diagnosed breast cancer cases from both public sector hospitals and diagnostic centers with respect to their completeness and concordance with BI-RADS standards, in the hope of identifying issues for improvement in reporting, particularly in areas which have an impact on patient care.

\section{Materials and methods}

A multicenter, prospective, descriptive study was carried out in the radiology sections of five institutions in Karachi, Pakistan. The Aga Khan University Hospital is a tertiary care private sector hospital. ${ }^{10}$ The Pakistan Naval Station Shifa Hospital is a 600-bed tertiary care public sector hospital serving inservice and retired naval personnel, with an established radiology section. ${ }^{11}$ The Advanced Radiology Center is a private sector diagnostic radiology facility in Karachi for the general public. ${ }^{12}$ The Karachi Institute of Radiotherapy and Nuclear Medicine is a public sector cancer diagnostic and treatment center in Karachi. ${ }^{13}$ The Civil Hospital Karachi is a 1900-bed tertiary care public hospital with an established radiology section. ${ }^{14}$ Approval for the study was obtained from the ethical review committee of Aga Khan University, after seeking consent from participating radiologists. The data were collected prospectively from May to October 2010.

Fifty consecutive mammograms reported as BI-RADS category 4 or 5 at each center were included in the study. All mammograms reported as BI-RADS category $0,1,2$, or 3 were excluded. Fifty reports were obtained from each study site, thus making a total of 250 reports. Category 4 and 5 mammography reports were collected from all the study centers, after obtaining consent from the corresponding consultant radiologists.

Mammogram reports were entered onto a questionnaire developed by the principal investigator in order to maintain confidentiality and privacy. This questionnaire was designed to extract data regarding the components of breast imaging reports taking into consideration the BI-RADS lexicon for describing malignant lesions in terms of clinical indication, breast density, lesion location and description, calcification, and status of axillary lymph nodes. The data included patient age, marital status, date of enrollment, registration number, institution from which the report had been generated, and the name of the reporting radiologist. In addition to clinical indication, the type of imaging service and findings based on detailed description of masses, classifications, and distribution and morphology of masses were also recorded.

Concordance of reporting was ascertained by comparing the radiologist's description for the given diagnosis with standard American College of Radiologist reports for BI-RADS 4 and 5 categories.

\section{Statistical analysis}

The data analysis was performed using the Statistical Package for the Social Sciences version 19.0 (SPSS Inc, Chicago, IL). Proportions were reported for all categorical variables. 
The Chi-square test was used to assess the completeness of reports for the two groups in accordance with the BI-RADS lexicon. For the variables stated above, a $P$ value of $<0.05$ at a $95 \%$ confidence interval was considered to be statistically significant.

\section{Results}

The mean age of the patients was $50 \pm 12$ years. The most frequent parameter described in the reports was location of the lesion within the breast followed by a description of the lesion. This was followed by reporting of breast parenchymal density, which was reported for $92 \%$ of mammograms (Table 1). The lesions were detected in the background of 61 fatty, 126 fibroglandular, 37 heterogeneously dense, and 26 dense breast parenchymal patterns. In total, 225 were bilateral mammograms and only 25 were unilateral mammograms. One hundred and twenty-six lesions were reported in the left breast and 124 lesions in the right breast. The upper outer quadrant was most frequently involved, and the lower inner quadrant was the least frequent site of the lesions described.

Clinical indication, breast parenchymal density, lesion location, and presence of calcification were all more frequently mentioned by private centers, with statistically significant $P$ values, while lymph node description parameters were more frequently stated by the government centers, again with a statistically significant $P$ value of 0.013 . Description of the masses by the two groups was not significantly different $(P=0.446$, Table 2). The general description of mass was equally good both for the private sector and the government/public sector.

\section{Discussion}

The BI-RADS system for mammographic reporting is now being used as a universal language in breast imaging centers to enable easy and understandable communication between the radiologist and the breast surgeon. In Pakistan, patients are referred for breast imaging not only by breast surgeons, but also by other specialists and family practitioners. Selfreferral is also common, so clear reports and further workup recommendations communicated in a clear language assume

Table I Percentages of parameters reported

\begin{tabular}{lll}
\hline Reporting criteria & $\mathbf{n = 2 5 0}$ & Percentages \\
\hline Clinical indication & $153 / 250$ & $61 \%$ \\
Breast density & $230 / 250$ & $92 \%$ \\
Lesion location & $240 / 250$ & $96 \%$ \\
Lesion description & $233 / 250$ & $93 \%$ \\
Lesion calcification & $140 / 250$ & $56 \%$ \\
Lymph nodes & $150 / 250$ & $60 \%$ \\
\hline
\end{tabular}

Table $2 P$ values for different parameters

\begin{tabular}{llll}
\hline $\begin{array}{l}\text { Reporting } \\
\text { criteria }\end{array}$ & $\begin{array}{l}\text { Government } \\
\text { institutions } \\
(\mathbf{n}=\mathbf{1 5 0})\end{array}$ & $\begin{array}{l}\text { Private } \\
\text { institutions } \\
(\mathbf{n}=\mathbf{1 0 0})\end{array}$ & $\begin{array}{l}\mathbf{P} \\
\text { values }\end{array}$ \\
\hline $\begin{array}{l}\text { Clinical indication } \\
\text { given }\end{array}$ & 55 & 94 & $<0.001$ \\
$\begin{array}{l}\text { Breast density } \\
\text { described } \\
\text { Lesion location } \\
\text { described }\end{array}$ & 139 & 97 & 0.004 \\
$\begin{array}{l}\text { Lesion description } \\
\text { (size and margins) }\end{array}$ & 148 & 100 & 0.010 \\
$\begin{array}{l}\text { Calcification } \\
\text { description }\end{array}$ & 70 & 93 & 0.446 \\
$\begin{array}{l}\text { Axillary lymph } \\
\text { nodes }\end{array}$ & 103 & 86 & $<0.001$ \\
\hline
\end{tabular}

even greater importance. The results of this study can be applied in our country and can be generalized to other developing countries where diagnostic and treatment services are not integrated or where radiologists do not routinely participate in multidisciplinary meetings.

Almost $40 \%$ of reports in this study did not mention the clinical indication for mammography. This is similar to a study conducted by Houssami et $\mathrm{al}^{4}$ in which clinical indication was not mentioned in about one-fifth of reports. In our study, breast density, location of the lesion, and a lesion description were given in $92 \%, 96 \%$, and $93 \%$ of reports, respectively. These are much higher percentages than those reported by Houssami et al, ${ }^{4}$ who found these to be $80 \%$, $75 \%$, and $77 \%$, respectively. The difference is most likely to be due to the training of radiologists regarding mammography reporting. All authors except one were either American board-certified or Fellows of the College of Physician and Surgeons, Pakistan. Both of these training programs include the American College of Radiology BI-RADS lexicon in their mandatory core syllabus, so these radiologists were likely to be better acquainted with the lexicon. Patient selection, patient age, and quality of mammograms may also affect visibility and description of the lesion. Reporting of breast parenchymal density is important, because it has an impact on accuracy of diagnosis and indeed the risk of having breast cancer. This was reported in $92 \%$ of cases, showing good compliance.

A statistically significant difference was noted in the description of clinical indication, breast parenchymal density, lesion location, and presence of calcification between public and private centers. This may be due to the frequent participation of private sector radiologists in multidisciplinary meetings and/or continuing medical education events. Training in BI-RADS leads to improved consensus 
agreement between experienced breast radiologists with regard to analysis of lesion features and final assessment. This has been documented earlier by Berg et al. ${ }^{15}$ In addition, most centers in the private sector get frequent feedback on their reports, either by the referring physicians or patients, because if there is inadequate or ambiguous information in the reports, the private centers are contacted for clarification. This also results in increased knowledge about what the clinician wants in the reports, but no such mechanism exists in the government sector.

Description of masses by the two groups was not significantly different. This may be due to the fact that mammograms reported as BI-RADS category 4 or 5 were included in the study, and every report had a lesion which needed a description. Lymph node description was significantly better stated by the government centers. This may be due to late presentation of patients with advanced disease due to low socioeconomic status and lack of awareness among less educated patients presenting in the government sector.

There are a few limitations to our study. The data were collected only from mammography reports and the actual mammograms were not seen at the time of data collection. Secondly, the lead radiologist knew that the data were being collected for the study. This might have affected the final reporting quality if the lead was also the reporting radiologist. The third limitation was that there were two private institutions and the rest were government institutions, which might have affected the results.

\section{Conclusion}

Our study shows that overall mammographic reporting for BI-RADS categories 4 and 5 in the private sector in Karachi, Pakistan is more in line with the BI-RADS lexicon, as compared with the government sector. Based on our findings, recommendations for the future are to arrange refresher courses for radiologists in the government sector and to improve the quality of reports. A checklist for style of breast imaging reports that includes key items should be introduced.

\section{Disclosure}

The authors report no conflicts of interest in this work.

\section{References}

1. Bhurgri Y, Bhurgri A, Nishter S, et al. Pakistan - country profile of cancer and cancer control 1995-2004. J Pak Med Assoc. 2006;56:124-130.

2. Nystom L, Anderson I, Bjurstam N, Frisell J, Nordenskjold B, Rurquist LE. Long term effects of mammography screening updated over view of the Swedish randomized trials. Lancet. 2002;359:909-919.

3. Gotzsche PC, Nielsen M. Screening for breast cancer with mammography. Cochrane Database Syst Rev. 2009;4:CD 001877.

4. Houssami N, Boyages J, Stuart K, Brennan M. Quality of breast imaging reports falls short of recommended standards. Breast. 2007;16:271-279.

5. American College of Radiology. ACR BI-RADS: Breast Imaging Reporting and Data System, Breast Imaging Atlas. Reston, VA: American College of Radiology; 2003.

6. Geller BM, Barlow WE, Ballard Barbash R, et al. Use of the American College of Radiology BI-RADS to report on the mammographic evaluation of women with signs and symptoms of breast disease. Radiology. 2002;222:536-542.

7. Berg WA, Campassi C, Langenberg P, Sexton MJ. Breast Imaging Reporting and Data System: inter- and intraobserver variabilty in feature analysis and final asessment. AJR Am J Roentgenol. 2000;174:1769-1777.

8. Baker JA, Kornguth PJ. Breast Imaging Reporting and Data System Standardized Mammography lexicon: observer variability in lesion description. AJR Am J Roentgenol. 1996;166:773-778.

9. Taplin SH , Ichikawa LE, Kerlikowske K, Ernster VL, Rosenberg RD, Yankaskas BC. Concordance of Breast Imaging Reporting and Data System assessment and management recommendations in screening mammography. Radiology. 2002;222:529-535.

10. The Aga Khan Hospital Karachi. C Aga Khan University; copyright. Available from: http://hospitals.aku.edu/Karachi/Pages/home.aspx. Accessed October 17, 2012

11. PN FLEET \& ESTABLISHMENTS. Available from: http://www. paknavy.gov.pk/hospitals.htm. Accessed October 17, 2012.

12. ADVANCED RADIOLOGY CLINIC. PagesPak.com; C2009-12. Available from: http://www.pagespak.com/company-ultrasound_clinics-advanced_radiology_clinic-\%20karachi-252228.html. Accessed October 17, 2012.

13. FUNCTIONS WebG(HRD); Pakistan Atomic Energy Commission, Islamabad. Available from: http://www.paec.gov.pk/kiran/functions. htm. Accessed October 17, 2012.

14. Civil Hospital. Available from: http://en.wikipedia.org/wiki/ Civil_Hospital. Accessed October 17, 2012.

15. Berg WA, D' Orsi CJ, Jackson VP, et al. Does training in the Breast Imaging Reporting and Data System (BI-RADS) improve biopsy recommendations or feature analysis agreement with experienced breast imagers at mammography? Radiology. 2002;224:871-880.
Cancer Management and Research

\section{Publish your work in this journal}

Cancer Management and Research is an international, peer-reviewed open access journal focusing on cancer research and the optimal use of preventative and integrated treatment interventions to achieve improved outcomes, enhanced survival and quality of life for the cancer patient. The journal welcomes original research, clinical \& epidemiological

\section{Dovepress}

studies, reviews \& evaluations, guidelines, expert opinion \& commentary, case reports \& extended reports. The manuscript management system is completely online and includes a very quick and fair peerreview system, which is all easy to use. Visit http://www.dovepress.com/ testimonials.php to read real quotes from published authors. 